\title{
Chlorpyrifos degradation in a Biomix: Effect of pre-incubation and water holding capacity
}

\author{
S. Fernández-Alberti ${ }^{1}$, O. Rubilar ${ }^{2}$, G.R. Tortella ${ }^{2}$, M.C. Diez ${ }^{1,2^{*}}$ \\ ${ }^{1}$ Chemical Engineering Department, Universidad de La Frontera, Temuco, Chile. ${ }^{2}$ Scientifical and \\ Technological Bioresource Nucleus, Universidad de La Frontera, PO Box 54-D, Teтuco, Chile. \\ *Corresponding author: mcdiez@ufro.cl
}

\begin{abstract}
Biobed system is a simple method to minimize point source contamination during manipulation of pesticides and is based on the adsorption and degradation potential of a biomix composed by top soil, peat, and straw and covered with a grass layer. In our study, the biomix was prepared with Andisol, peat and straw in a volumetric proportion of 1:1:2, and adsorption and degradation studies were done. Degradation of chlorpyrifos (160 mg a.i. $\left.\mathrm{kg}^{-1}\right)$ and formation of TCP (3, 5, 6-trichloro-2-pyrinidol) at different pre-incubation times $(0,15$ and 30 days) and with different moisture contents (40,60 and $80 \%$ of water holding capacity) were evaluated, ligninolytic enzyme activity and microbial respiration in the biomix were periodically analyzed. Adsorption isotherms were fitted using Freundlich and linear models for Andisol and the biomix. The adsorption assays demonstrated that biomix has a higher capacity to retain chlorpyrifos than top soil. The pre-incubation period, WHC and the concentration of the chlorpyrifos of the biomix influenced the degradation of the contaminant and TCP formation as well as the biological activities in the biomix. The TCP was formed during the first steps of chlorpyrifos degradation and was later degraded in the biomix under all studied conditions. In conclusion, biomix with Andisol, peat and straw (1:1:2), pre-incubated by 15 days and incubated with $60 \%$ of WHC is capable to degrade chlorpyrifos efficiently.
\end{abstract}

Keywords: Biomix, Andisol, pre-incubation time, water holding capacity, chlorpyrifos. 


\section{Introduction}

Pesticides play an important role in the success of modern farming and food production. However, inadequate management of pesticides can lead to contamination of surface and groundwater, because pesticide residues can persist in the environment for variable periods of time (Anwar et al., 2009). The release of pesticides into the environment generally occurs by diffuse (nonpoint) or localized (point) sources. Point sources such as spillages, tank filling, or cleaning the spraying equipment have been identified as the major contamination risks (Jaeken and Debaer, 2005). These activities are often performed specifically on-farm sites, generally near a water supply, therefore, high concentrations of pesticide residues can be found in these places (Castillo and Torstensson, 2007).

A simple, low-cost and low maintenance technology (biobed) was developed in Sweden to reduce point-source contamination by pesticides (Torstensson and Castillo, 1997). Biobeds are based on the adsorption and degradation of pesticides by a biomix composed by top soil, peat, and straw and covered with grass. Each component in the biomix plays an important role in the dissipation of the pesticides in this system. Straw stimulates growth of ligninolytic microorganisms and the production of extracellular ligninolytic enzymes as peroxidases and phenoloxidases. In addition, straw promotes growth of microorganisms, such as white-rot fungi, with the ability to degrade those pesticides characterized by an aromatic ring structure (Castillo et al., 2008). On the other hand, peat provides sorption capacity, high water retention ability regulating moisture in the biobed and, also abiotic degradation of pesticides (Torstensson and Castillo, 1997; Castillo et al., 2008). Soil is an important source of microorganisms in the biomix and bacteria can act synergistically with fungi to degrade pesticides (Castillo et al., 2008). The presence of soil bacteria can enhance the extent of pesticide degradation (Maya et al., 2011) as well as degradation of other organic pollutants (Kotterman et al., 1998; Castillo et al., 2008). Furthermore, soil has the ability to adsorb pesticides in the biobed, due to its humus and clay contents (Castillo and Torstensson, 2007).

Apart from the composition of the biomix, an important factor for the efficacy of biobed is age or maturity of the biomix before its use in the pesticide degradation. The progressive biodegradation of the component generates a series of microbial communities and enzymatic activities that enables an efficient dissipation of pesticides in the biobed system and avoids metabolite accumulation (Castillo et al., 2008). Nevertheless, little information has been reported in the literature about the influence of this parameter in pesticide degradation in a biobed.

The role of the type of soil in the biomix of the biobed has not been studied deeply. However, soil plays an important role in pesticide degradation (Castillo et al., 2008; Diez, 2010; Maya et al., 2011). The effect of soil types used for biomix preparation was studied by Fogg and Boxall (2004). They found that there were no significant differences in the biobed performance. Nevertheless, the soils used in their study had a low level of organic matter (OM) compared with soil of the south of Chile (Andisol and Ultisol). Chilean Andisol as component of biomix could be an effective support for this system due to its high OM content $(>10 \%)$ with great affinity for organic pollutants due to the presence of humic acid, fulvic acid and reactive clay such as $\mathrm{Al}$ and $\mathrm{Fe}$ hydroxide groups (Diez et al., 1999; Cea et al., 2007).

The moisture level in the biobed is also a relevant parameter to promote different microbial environments that can influence the oxygen level, the microbial activity and the amount of pesticide in solution. 
According to Castillo and Torstensson (2007), low levels of moisture, such as $30 \%$ WHC may limit the microbial activity and the amounts of pesticides in solution; moisture level of $60 \%$ WHC may give enough water for microbial processes, solubilization of pesticides, and adequate pore space for oxygen to support aerobic processes and, higher solubilization of pesticides occurs at $90 \% \mathrm{WHC}$, but oxygen deficiency in the system could be expected. Under these conditions aerobic microbial processes will be limited and anaerobic processes may prevail; moreover, it may create a risk for transport of chemicals outside the biobed (Castillo and Torstensson, 2007).

In Chile, biobed tehnology has not been established, yet. Therefore, the aim of our study was to evaluate the adsorption and degradation of chlorpyrifos in a biomix composed by an Andisol of southern Chile, peat and straw. The effect of pre-incubation time and water holding capacity of the biomix in chlorpyrifos degradation, TCP formation and biological parameters, such as microbial respiration and ligninolytic enzyme activity, were evaluated.

\section{Materials and Methods}

\subsection{Chemicals}

Analytical grade (99\%) chlorpyrifos (O,O-diethyl$O$-(3,5,6-trichloro-2-pyridyl) phosphorothiate) and TCP (3,5,6-trichoro-2-pyridinol) were purchased from Sigma-Aldrich. Commercial formulated chlorpyrifos (Clorpirifos S480) of $48 \% \mathrm{w} / \mathrm{v}$ was purchased from ASP Chile. MBTH (3-methyl-2-benzothiazolinone hydrazone), DMAB (3-(dimethylamino) benzoic acid) were purchased from Aldrich. All other chemicals and solvents were of analytical reagent grade (Merck).

\subsection{Preparation of biomix:}

The biomix was prepared by mixing top soil (without chlorpyrifos application history), commercial peat and wheat straw (2 cm long) in the volumetric proportions of 1:1:2. The used top soil was an Andisol from Southern Chile, Gorbea locality belonging to Freire series (Typic Placudands) with loamy texture (CIREN, 2003), sampled from 0-20 cm deep, air dried at room temperature and sieved through a $2 \mathrm{~mm}$ mesh. The soil has pH 5.5, $8.5 \%$ organic carbon (OC), $37.4 \%$, sand $41.7 \%$ silt and $20.9 \%$ clay. The commercial peat has $33.4 \%$ cellulose and $21.9 \%$ lignin. Wheat straw has $9.9 \%$, lignin $41.8 \%$, cellulose organic $66.1 \%$, matter $\mathrm{pH} 5.9$ and $0.56 \%$ total nitrogen The biomix was stored in a polypropylene bag at $4{ }^{\circ} \mathrm{C}$ until use. The resulting biomix has $\mathrm{pH}$ 6.0, 17\%organic carbon and $0.91 \%$ nitrogen $(\mathrm{C} / \mathrm{N}=19)$.

\subsection{Adsorption study}

The assay was performed in triplicate in $50 \mathrm{~mL}$ glass tubes containing $0.2 \mathrm{~g}$ sample (top soil and biomix pre-incubated for 15 days), with $20 \mathrm{~mL}$ chlorpyrifos concentration of 5, 10, 20, 30 and $40 \mathrm{mg} \mathrm{L}^{-1}$. $\mathrm{CaCl}_{2} 0.1$ mol L $\mathrm{L}^{-1}$ was used as background electrolyte solution. The assay was performed at the natural $\mathrm{pH}$ value of the biomix (6.0) and top soil (5.5). A preliminary kinetic study indicated that equilibrium between the amount of pesticide adsorbed and the amount in solution was reached within $8 \mathrm{~h}$. However, a period of 12-h was used in order to ensure the equilibrium state in this study. After equilibrium, $5 \mathrm{~mL}$ of each sample were centrifuged at $10000 \mathrm{rpm}$ (Eppendorf $5804 \mathrm{R}$ centrifuge) for $10 \mathrm{~min}$ and then passed through a membrane filter PTFE of $0.22 \mu \mathrm{m}$ pore size. The chlorpyrifos 
concentration in the supernatant was determined by High Performance Liquid Chromatography (HPLC).

\subsection{Degradation studies}

In the first experiment, the effect of biomix pre-incubation at different times on the degradation efficiency was evaluated. The biomix with $60 \%$ of water holding capacity (WHC) was pre-incubated in polypropylene bags for 0,15 and 30 days at $25 \pm 1^{\circ} \mathrm{C}$. Then, samples of each pre-incubated biomix ( $10 \mathrm{~g}$ dry weight) were placed in glass jars of $500 \mathrm{~mL}$ and were spiked with a solution of commercial formulated chlorpyrifos (Clorpirifos S480, diluted in water to reach concentration of $160 \mathrm{mg}$ a.i. $\mathrm{kg}^{-1}$ ). Samples were incubated in the dark at $25 \pm 1^{\circ} \mathrm{C}$ for 40 days with moisture content of $60 \%$ of WHC by adding distilled water. Each experiment was carried out in triplicate under destructive sampling mode. Biomix without chlorpyrifos was used as control. After 0, 5, 10, 20, 30 and 40 days of incubation, the residual chlorpyrifos, 3,5,6-trichloro2-pyridinol (TCP) formation and ligninolytic enzyme activity were measured. The pre-incubation time of biomix that showed the highest chlorpyrifos removal was selected for further studies. In parallel, microbial respiration of the biomix $\left(\mathrm{CO}_{2}\right.$ evolution) was conducted under the same conditions described above.

In a second experiment, the effect of water holding capacity in biomix degradation efficiency was assessed. Samples of biomix (10 g dry weight) preincubated for 15 days were placed in glass flasks (500 $\mathrm{mL}$ ) and distilled water was added to obtain samples with 40, 60 and 80\% water holding capacity (WHC). The biomix was spiked with a stock solution of commercial formulated chlorpyrifos (Clorpirifos S480, diluted in water to reach concentration of $160 \mathrm{mg}$ a.i. $\left.\mathrm{kg}^{-1}\right)$. After $0,5,10,20,30$ and 40 day incubation in the dark at $25 \pm 1^{\circ} \mathrm{C}$, the residual chlorpyrifos, TCP formation and ligninolytic enzyme activity were measured. Each experiment was carried out in triplicate under destructive sampling mode.

\subsection{Calculation of adsorption and degradation parameters}

To evaluate the sorption capacity of the different substrates, the experimental data were fitted to the empirical Freundlich-type isotherm (Eq.[1]):

$$
C s=K_{f} \cdot C_{e}^{1 / n}
$$

Where $C s$ is the mass of chlorpyrifos adsorbed per mass of substrate $\left(\mathrm{mg} \mathrm{kg}^{-1}\right)$; $C e$ is the concentration of chlorpyrifos remaining in the solution $\left(\mathrm{mg} \mathrm{L}^{-1}\right)$ after equilibration; $K f$ is the Freundlich distribution coefficient $\left(\mathrm{L} \mathrm{kg}^{-1}\right)$; and $1 / n$ is an exponential empirical parameter that accounts for nonlinearity in sorption behavior (Sposito, 1984). If $1 / n=1$, the adsorption isotherm is linear, i.e. $K f=K d$. The $K_{d}$ value was normalized to the organic carbon (OC) content of each sample to calculate $K_{o c}$ (Eq. [2]):

$$
K_{o c}=K_{d} / f_{\text {oc }}
$$

Where $f$ oc is the percent fraction of organic carbon of the biomix components or biomix.

The chlorpyrifos degradation in biomix was described using the first-order kinetic equation as $\mathrm{C}=\mathrm{C} 0$ $\mathrm{e}^{-k t}$, and from the equation, we obtained (Eq. [3]):

$$
t_{1 / 2}=\operatorname{Ln}(2) / k
$$

Where $k$ is the first order-rate constant $\left(\mathrm{d}^{-1}\right)$.

The leaching potential of chlorpyrifos was determined by the groundwater ubiquity score (GUS) index (Eq. [4]),_(Gustavson, 1989). This index is based on chemical adsorption (Koc) and persistence (t $1 / 2)$ :

$$
G U S=\log _{10}\left(t_{1 / 2}\right) \cdot\left[4-\log _{10}\left(K_{o c}\right)\right]
$$




\subsection{Analysis}

Ligninolytic enzyme activity:

The analysis was performed using the MBTH/DMAB assay according to the methodology described by Castillo et al. (1994). To extract the enzymes, samples of the biomix ( $10 \mathrm{~g}$ dry weight) were weighed in Erlenmeyer flasks and $50 \mathrm{~mL}$ of $100 \mathrm{mM}$ succinatelactate buffer ( $\mathrm{pH} 4.5)$ were added to each sample. The flasks were shaken at $100 \mathrm{rpm}$ for $2 \mathrm{~h}$, and 10 $\mathrm{mL}$ of the supernatant were collected and centrifuged at $4000 \mathrm{rpm}$ for $20 \mathrm{~min}$ and filtered through $0.45 \mu \mathrm{m}$ membrane (National Scientifics filter unit). The reaction mixture contained $300 \mu \mathrm{L}$ of $6.6 \mathrm{mM}$ DMAB, $100 \mu \mathrm{L}$ of $1.4 \mathrm{mM} \mathrm{MBTH}, 30 \mu \mathrm{L}$ of $20 \mathrm{mM} \mathrm{MnSO}_{4}$, $10 \mu \mathrm{L}$ of $10 \mathrm{mM} \mathrm{H}_{2} \mathrm{O}_{2}$, and $1560 \mu \mathrm{L}$ of the sample in a $100 \mathrm{mM}$ succinic/lactic acid buffer $\mathrm{pH}$ 4.5. The reaction was followed at $590 \mathrm{~nm}\left(\varepsilon=0.053 \mu \mathrm{M}^{-1} \mathrm{~cm}^{-1}\right)$ in a spectrophotometer (Spectronic Genesis ${ }^{\mathrm{TM}} 2 \mathrm{PC}$ ). As no correction was made for the possible presence of lignin peroxidase (LiP) and laccase (Lac) activity, this measurement may represent the sum of manganese peroxidase, LiP and laccase (Castillo and Torstensson, 2007).

\subsection{Microbial respiration}

The $\mathrm{CO}_{2}$ produced in the biomix was evaluated by means of incubation experiments according to the methodology of Iannotti et al. (1994). The biomix (50 g) was placed in a $1 \mathrm{~L}$ flask with a vial containing 10 $\mathrm{mL}$ of $0.5 \mathrm{~mol} \mathrm{~L}^{-1} \mathrm{NaOH}$ and a vial with $10 \mathrm{~mL}$ distilled water for maintaining a humid atmosphere. The flask was hermetically sealed and incubated at $25^{\circ} \mathrm{C}$. The $\mathrm{CO}_{2}$ captured in the $\mathrm{NaOH}$ solution was determined by titrating the remaining alkali with $0.1 \mathrm{~mol} \mathrm{~L}^{-1}$ $\mathrm{HCl}$ after precipitation of carbonate with $0.1 \mathrm{~mol} \mathrm{~L}^{-1}$
$\mathrm{BaCl}_{2}$. The respiration was expressed as accumulated mg CO 2100 g biomix $^{-1}$.

\subsection{Extraction and quantification of chlorpyrifos}

The residual concentration of chlorpyrifos in biomix was determined by HPLC after extraction with acidified acetone (acetone + water + concentrated phosphoric acid, $98+1+1$ by volume) per gram of substrate (Racke et al., 1996). Briefly, $5 \mathrm{~g}$ (in duplicate) of biomix were mixed with $30 \mathrm{~mL}$ of acidified acetone and incubated under shaking ( $350 \mathrm{rpm}$ ) for $2 \mathrm{~h}$ at 25 ${ }^{\circ} \mathrm{C}$. Later, the samples were sonicated for $30 \mathrm{~min}$, centrifuged at $10000 \mathrm{rpm}$ and filtered with PTFE membrane $(0.2 \mu \mathrm{m}$ pore size; Millipore). Samples were injected in a Merck Hitachi L-7100 pump, a Rheodyne 7725 injector with a $20 \mu \mathrm{L}$ loop and a Merck Hitachi L-7455 diode array detector. The detector was set at $290 \mathrm{~nm}$ and the column was a C18 column (Superspher RP-C18, $5 \mu \mathrm{m} 4.6 \times 150 \mathrm{~mm}$ ). The mobile phase consisted of $60 \% \mathrm{CH}_{3} \mathrm{CN}$ and $40 \%$ water/acetic acid $(95.3 / 4.3 \mathrm{v} / \mathrm{v})$ with a flow rate of $1 \mathrm{~mL} \mathrm{~min}^{-1}$ at 25 ${ }^{\circ} \mathrm{C}$. The chlorpyrifos and TCP recovery was more than $85 \%$. The retention times were $3.7 \mathrm{~min}$ for TCP and $23 \mathrm{~min}$ for chlorpyrifos, the detection limits were 0.02 and $0.01 \mathrm{mg} \mathrm{L}^{-1}$ in the aqueous phase for TCP and chlorpyrifos, respectively. The residual chlorpyrifos was calculated as a percentage of the initial chlorpyrifos concentration.

\subsection{Statistical analysis}

All the experiments were carried out in triplicate. Data were statistically analyzed by one-way analysis of variance (ANOVA), where statistical differences were observed, and means were separated using Tukey's minimum significant difference test $(p<0.05)$. 


\section{Results and Discussion}

\subsection{Pesticide adsorption in biomix and top soil}

Chlorpyrifos adsorption in biomix and top soil was adjusted to both linear and Freundlich equations, which were used to calculate the adsorption parameters $\left(K_{f}, 1 / n\right)$ (Table 1$)$. Adsorption was influenced by both the physicochemical properties of the pesticide and the type of material used as adsorbent $(\mathrm{pH}$ and organic matter content). The biomix showed the highest adsorption capacity by chlorpyrifos, with $\mathrm{K}_{f}$ value of 4920, compared with soil, where $\mathrm{K}_{f}$ value was 3304 . The $1 / n$ values were less than 1 (L-type isotherms) for both biomix and Gorbea soil indicating a strong affinity between the adsorbent and the adsorbate. These results can be explained by the high or ganic carbon content and $\mathrm{pH}(24.1 \%, \mathrm{pH}$ 6.0) of the biomix compared with Gorbea soil that contains $8.5 \%$ of organic carbon and $\mathrm{pH}$ 5.5. Similar results were obtained by Romyen et al. (2007), who demonstrated that the adsorption of chlorpyrifos in different agricultural byproducts and soil could be correlated to organic carbon content. On the other hand, the high adsorption of chlorpyrifos by soil or biomix is explained by its hydrophobic character $\left(\log \mathrm{K}_{\mathrm{ow}} 4.7\right)$. The adsorption parameter for the linear partitioning model was calculated from Eq. [2], in which the partition coefficient $\left(\mathrm{K}_{d}\right)$ in the biomix was 2753 and 601.7 in soil. However, the adsorption parameter $\mathrm{K}_{\mathrm{oc}}$ value for biomix was substantially higher than the value for Gorbea soil corroborating the high affinity of chlorpyrifos by the biomix (Table 1).

Table1. Freundlich and linear parameters obtained of the sorption isotherms of chlorpyrifos in biomix (50\% straw, $25 \%$ peat, $25 \%$ soil) and soil in $\mathrm{CaCl}_{2} 0.1 \mathrm{~mol} \mathrm{~L}^{-1}$.

\begin{tabular}{lcccccc}
\hline \multicolumn{3}{l}{ Freundlich } & \multicolumn{3}{c}{ Linear } \\
\hline Biomix & $\boldsymbol{K}_{f}^{a}$ & $\mathbf{1 / n}$ & $\mathbf{R}^{\mathbf{2}}$ & $\boldsymbol{K}_{\boldsymbol{d}}^{\mathbf{b}}$ & $\boldsymbol{K}_{\boldsymbol{c c}}$ & $\mathbf{R}^{\mathbf{2}}$ \\
Soil & 4920 & 0.612 & 0.97 & 2753 & 11390 & 0.96 \\
\hline & 3304 & 0.483 & 0.99 & 601.7 & 7079 & 0.84 \\
\hline
\end{tabular}

Parameters obtained of non-linear (a) and linear (b) regression of the experimental data.

\subsection{Chlorpyrifos degradation at different pre- incubation times}

The effects of different pre-incubation times $(0,15$ and 30 days) of the biomix on chlorpyrifos degradation (160 $\mathrm{mg}$ a.i. $\left.\mathrm{kg}^{-1}\right)$ and TCP formation are presented in Figure 1. Values of rate constant $(\mathrm{k})$, half-life $\left(\mathrm{t}_{1 / 2}\right), \mathrm{r}^{2}$ and results of the statistical analysis for LSD $(p<0.05)$ are reported in Table 2 for the pesticide. The biomix pre-incubated for 15 days showed the highest degradation of chlorpyrifos (Figure 1a). At the end of the incubation period (40 days), the degradation of chlorpyrifos was $70 \%$ in the biomix pre-incubated for 15 days, $58 \%$ in the biomix preincubated for 30 days and $50 \%$ in the biomix without pre-incubation. 


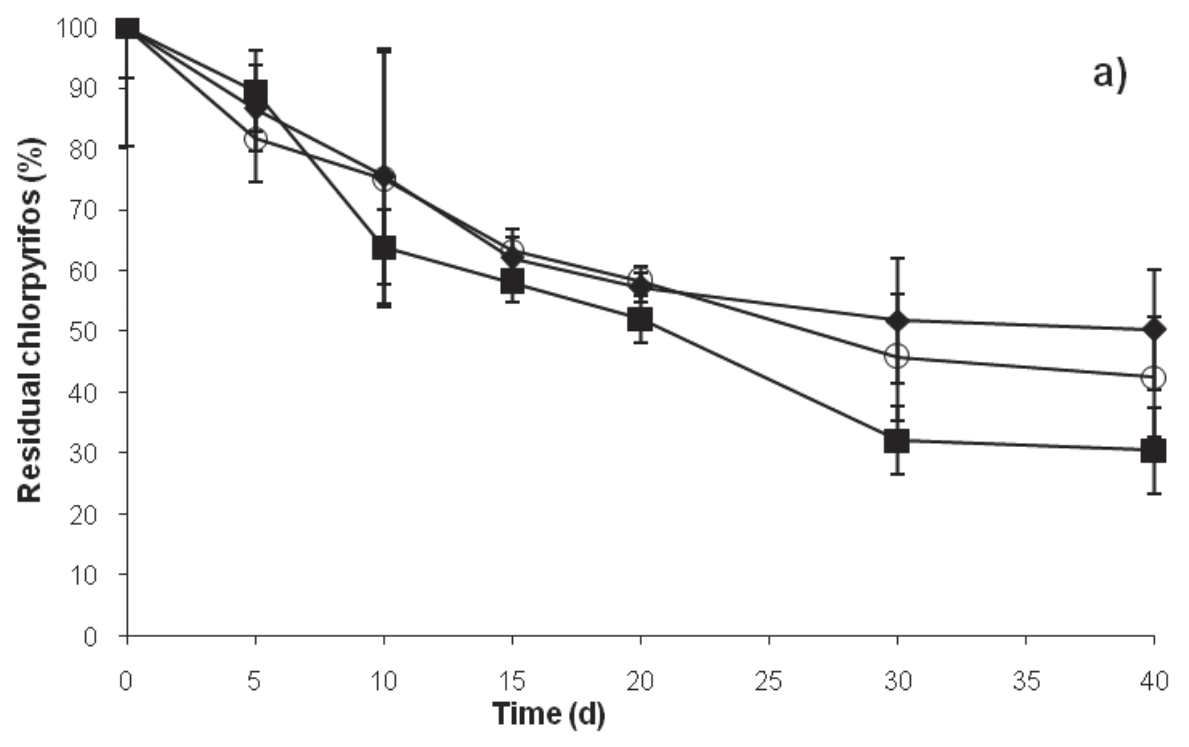

$\rightarrow 0(\mathrm{~d}) \quad \rightarrow-15(\mathrm{~d}) \quad \rightarrow 30(\mathrm{~d})$

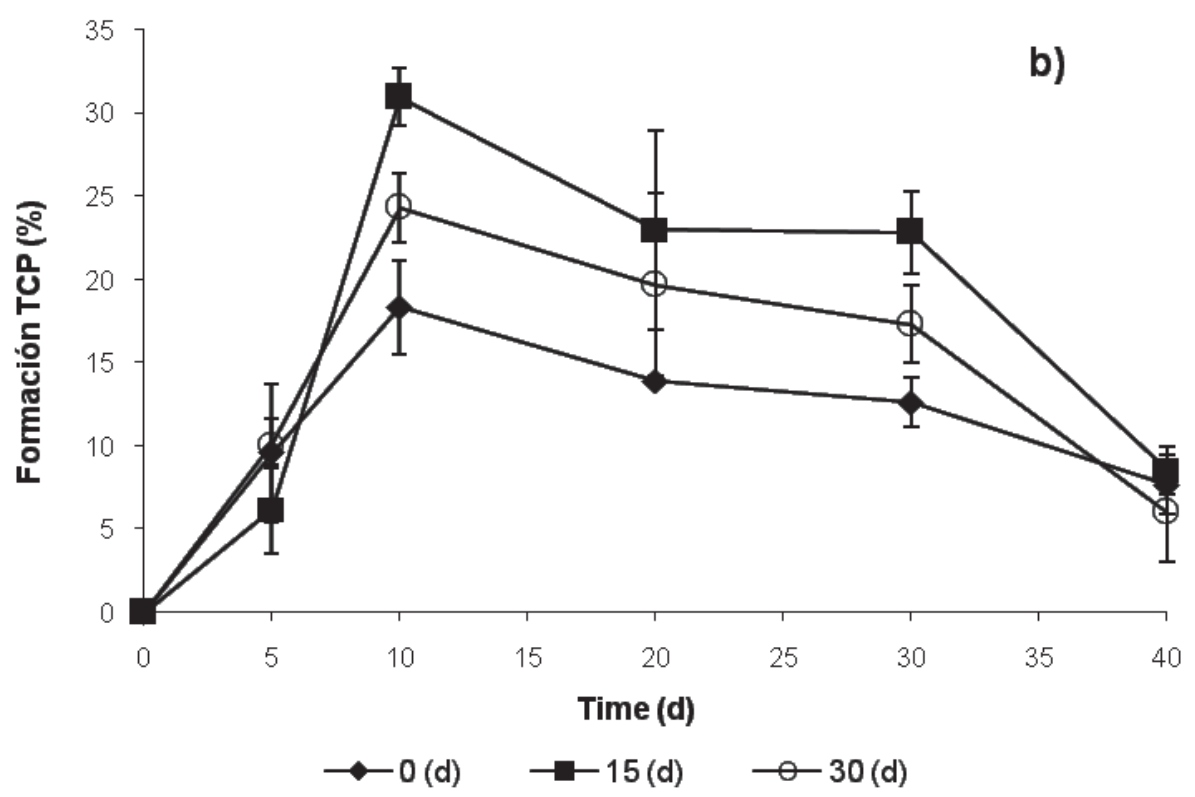

Figure 1. Effect of different times of pre-incubation (0,15 and 30 days) in chlorpyrifos degradation (a) and TCP formation (b) at initial concentration of $160 \mathrm{mg}^{\mathrm{a} .1 \mathrm{~kg}^{-1}}$ in biomix and $60 \%$ of WHC. 
Degradation of chlorpyrifos was faster in the biomix pre-incubated for 15 days $\left(t_{1 / 2}=19.7\right.$ days $)$ than in the biomix without pre-incubation ( $\mathrm{t}_{1 / 2}=39.9$ days), showing the relevance of pre-incubation before using the biomix with the contaminant. However, no significant differences $(p<0.05)$ were found when biomix was pre-incubated for 15 and 30 days (Table 2). Our values of $t_{1 / 2}$ are low compared with values reported in the literature for chlorpyrifos in some biomix in Europe. (Fogg et al., 2003; Coppola, et al., 2007; Vischetti et al., 2008). These authors reported half life value for chlorpyrifos between 43 and 59 days, depending on the used biomix. For example, Coppola (2007) reported half-life values of 52 and 37 days for chlorpyrifos $\left(100 \mathrm{mg} \mathrm{kg}^{-1}\right)$ in two organic substrates prepared with urban-waste compost and garden compost with straw, respectively. The differences in the results may be associated with the composition of the biomix. In our case, we used an Andisol with high organic carbon content (8.5\%), acidic $\mathrm{pH}$ (5.5) and high level of microorganisms that promote the adsorption and the degradation of this type of molecules diminishing half-life of the contaminant (Cea et al., 2007; Tortella et al., 2010). In addition, Getzin (1981) attributed the wide variation in the half-life of pesticides to different factors such as $\mathrm{pH}$, temperature, moisture, organic carbon content and the pesticide formulation. Abiotic factors make the hydrolysis of chlorpyrifos possible, as it has been reported by Racke et al. 1996. In relation to this last statement, the possibility that chlorpyrifos may also be degraded by abiotic hydrolytic processes cannot be excluded.

Table 2. Half-life ( $\mathrm{t} 1 / 2)$, rate constant $(k)$ and GUS (Groundwater Ubiquity Score), index of the biomix with $60 \%$ WHC at different pre-incubation times $(0,15$ and 30 days).

\begin{tabular}{cccccc}
\hline Pre-incubation (d) & $\begin{array}{c}\text { WHC } \\
(\mathbf{\%})\end{array}$ & $\mathbf{k}\left(\mathbf{d}^{-\mathbf{1}}\right)$ & $\mathbf{t}_{1 / 2}$ & $\mathbf{r}^{2}$ & GUS \\
\hline 0 & 60 & 0.020 & $39.9 \mathrm{a}$ & 0.86 & 0.28 \\
15 & 60 & 0.040 & $19.7 \mathrm{~b}$ & 0.97 & 0.14 \\
30 & 60 & 0.030 & $21.8 \mathrm{~b}$ & 0.97 & 0.18 \\
\hline
\end{tabular}

The GUS index is used universally for evaluating the potential of contamination of groundwater and leaching of pesticide into surface waters through drainage systems. If its value is less than 1.8 , the pesticide is considered non-leachable and the risk of groundwater contamination is low, whereas if its value is more than 2.8, the risk of contamination is high (Gustavson, 1989). In our study, all values were less than 1.8 , inferring that the risk of lixiviation of chlorpyrifos is very low (Table 2). This effect is due to the preincubated biomix, which has a good adsorption by the pesticide, expressed with a higher adsorption coefficient of organic carbon $\left(\mathrm{K}_{O C}\right)$. Henriksen et al. (2003) demonstrated that a biobed with a fresh biomix (without pre-incubation) that is subjected to high hydraulic loads produces high leaching of pesticides.

\subsection{TCP formation at different pre-incubation times}

The formation of 3,5,6-trichloro-2-pyridinol (TCP), the first hydrolysis metabolite of chlorpyrifos, was observed during the incubation period and it was in- 
fluenced by the pre-incubation period (Figure 1b). The highest value of TCP was obtained when the biomix was pre-incubated by/for 15 days and the lowest when the biomix was not pre-incubated. Furthermore, the highest formation of TCP was obtained after 10 days of incubation (31, 24 and $18 \%$ for 15, 0, and 30 days of pre-incubation, respectively. After that, TCP formation decreased in all samples up to approximately $9 \%$ after 40 days of incubation by the degradation of the native microbial population in the biomix. Maya et al. (2011) reported that bacterial community isolates from soil have high affinity for degradation of both chlorpyrifos and TCP. Sandar and Kole (2005) obtained similar results (30\% TCP formation) using clay soils contaminated with 100 fold field dose of chlorpyrifos. The determination of TCP is essential during biological degradation of chlorpyrifos as TCP is more soluble than chlorpyrifos $\left(49.1 \mathrm{~g} \mathrm{~L}^{-1}\right.$ at $\left.25^{\circ} \mathrm{C}\right)$, has a longer half-life ( $>65$ days) and has shown to have antimicrobial properties (Racke et al., 1988), therefore, it could affect the biological process of degradation.

During the pre-incubation period, physical and chemical changes occur in the biomix, due to different reactions caused by the proliferation of different microbial populations, which could accelerate the decompo- sition of biodegradable organic compounds. Castillo et al. (2008) reported that biomix age is an important factor in the behaviour of the biobed because each component of biomix has its own biodegradation process, which generates proliferation of microbial communities involved in the pesticide degradation.

\subsection{Chlorpyrifos degradation at different water holding capacity}

The effect of three moisture levels $(40,60$, and $80 \%$ of WHC) of biomix pre-incubated for 15 days on chlorpyrifos degradation (160 mg a.i. $\mathrm{kg}^{-1}$ ) and TCP formation are presented in Figure 2. Values of rate constant $(\mathrm{k})$, half-life $\left(\mathrm{t}_{1 / 2}\right), \mathrm{r}^{2}$ and results of the statistical analysis for LSD $(p<0.05)$ are reported in Table 3 for the pesticide. The biomix with $60 \%$ of WHC showed the highest degradation of chlorpyrifos (Figure 2a). At the end of the incubation period (40 days), the degradation of chlorpyrifos was approximately 70,64 and $56 \%$ in the biomix with 60,40 and $80 \%$ of WHC, respectively. The humidity in the biomix is very important due to a great part of the biological activity and physical and chemical processes are influenced by water content. 

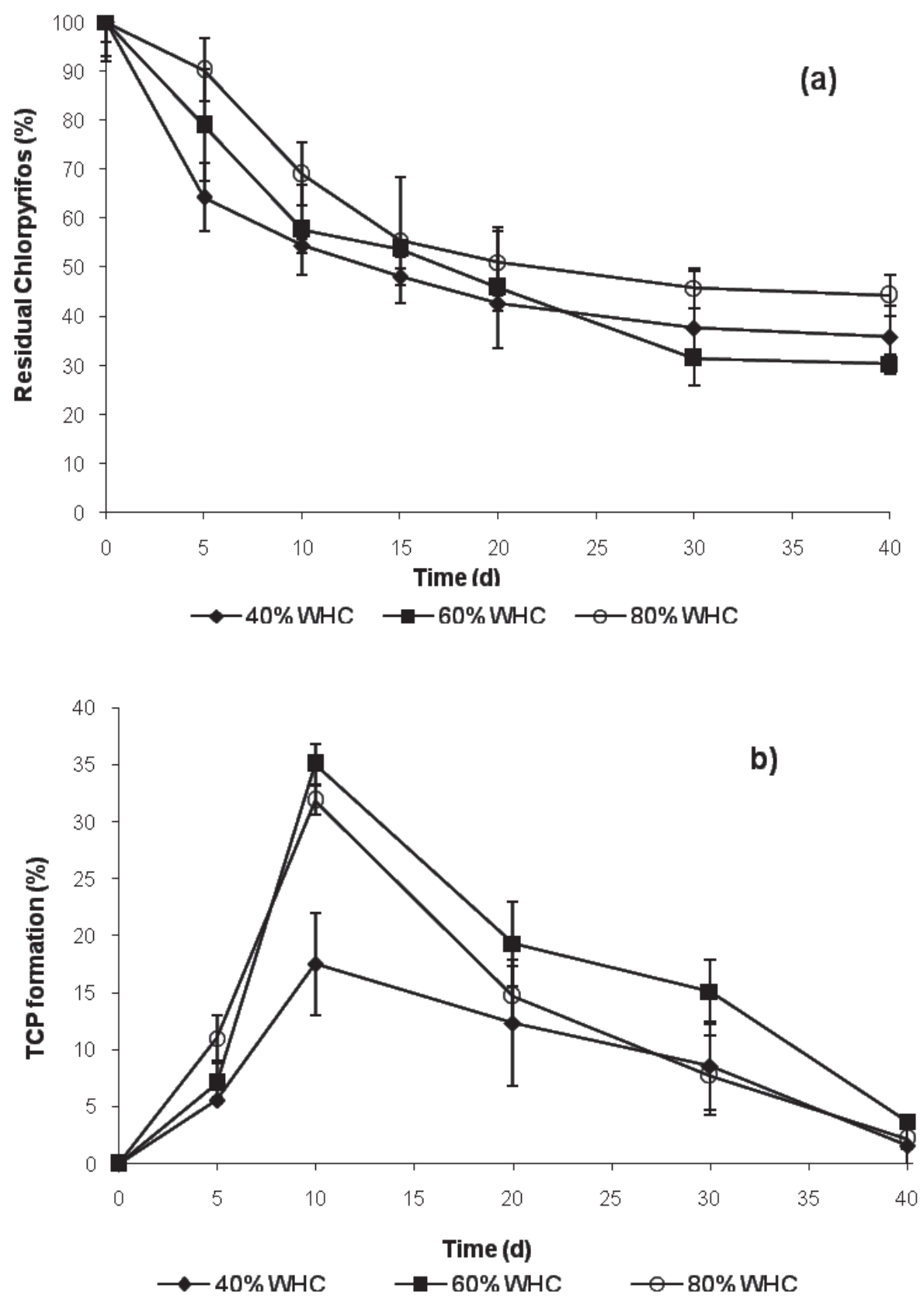

Figure 2. Effect of different water holding capacity (40, 60 and 80\%) in chlorpyrifos degradation (a) and TCP formation (b) at initial chlorpyrifos concentration of $160 \mathrm{mg} \mathrm{a}^{\mathrm{i}} \mathrm{kg}^{-1}$ in biomix, pre-incubation of 15 days. 
The variation of WHC in the biomix affected the $\mathrm{t}_{1 / 2}$ values of chlorpyrifos and significant differences were found $(p<0.05)$ among treatments (Table 3). Degradation of chlorpyrifos was faster in the biomix with $60 \%$ of WHC ( $\mathrm{t}_{1 / 2}=22.1$ days $)$ than in the biomix with $40\left(\mathrm{t}_{1 / 2}=37.8\right.$ days $)$ and $80 \%$ of WHC (31.3 days), showing the relevance of the humidity in the biomix for the degradation of the pesticide.
The $t_{1 / 2}$ increased with the increment in the chlorpyrifos concentration twice or more times in respect to the low concentration of chlorphyrifos (160 $\mathrm{mg} \mathrm{kg}^{-}$ 1) (Fernández, 2010). Similar results were reported by Sandar and Kole (2005), they found that in the samples with 1, 10 and 100 times the field dose, half-life times of chlorpyrifos were 20,23 and 37 days respectively.

Table 3. Half-life ( $1 / 2$ ), rate constant ( $k$ ) and GUS (Groundwater Ubiquity Score), index of the biomix preincubated for 15 days with different water holding capacity (40, 60 and $80 \%$ ).

\begin{tabular}{cccccc}
\hline Pre-incubation (d) & $\begin{array}{c}\text { WHC } \\
(\mathbf{\%})\end{array}$ & $\mathbf{k}\left(\mathbf{d}^{-1}\right)$ & $\mathbf{t}_{1 / 2}$ & $\mathbf{r}^{2}$ & GUS \\
\hline 15 & 40 & 0.025 & $37.8 \mathrm{a}$ & 0.94 & 0.26 \\
15 & 60 & 0.035 & $22.1 \mathrm{~b}$ & 0.95 & 0.15 \\
15 & 80 & 0.020 & $31.3 \mathrm{c}$ & 0.92 & 0.22 \\
\hline
\end{tabular}

The GUS index was lower $(0.15)$ in the biomix with $60 \%$ of WHC and increased to 0.26 in the biomix with $40 \%$ of WHC and to 0.22 in the biomix with $80 \%$ of WHC, showing that the humidity content in the biomix could modify the behaviour of the pesticide in the biomix (Table 3). However, these values are under the critical value of 1.8. Therefore, the pesticide is considered as non-leachable and without risk of groundwater contamination.

\subsection{TCP formation at different water holding capacity}

Figure $2 \mathrm{~b}$ shows the formation of TCP in the biomix incubated with different WHC. We can see that TCP formation increased with the increment of moisture in the biomix. The highest values of TCP were obtained after 10 days of incubation, when WHCs in the biomix were 60 and $80 \%$ (35 and $32 \%$, respectively). After that, TCP formation decreased down to approximately $3 \%$ after 40 days of incubation. Similar results were obtained by Castillo and Torstensson (2007).
The authors compared the effect of three moisture levels $(30 \%, 60 \%$, and $90 \%$ of $\mathrm{WHC})$ in laboratory biobed studies and demonstrated that $60 \%$ moisture of WHC gave the highest dissipation of most tested pesticides, whereas moisture of 30 and $90 \%$ WHC limited the microbial activity. Our results pointed out the relevance of the regulation of moisture in the biomix of the biobed. However, it may be a difficult task in farm biobeds; therefore, it is important to include peat or similar water-binding materials in the biomix to maintain an adequate level of moisture in the system.

The moisture condition is also an important factor especially in chlorpyrifos hydrolysis. Racke et al. (1996) reported that chlorpyrifos hydrolysis was greatly accelerated under low moisture condition (< $20 \%$ ). In our assays, $60 \%$ water holding capacity was maintained during all time of incubation of the biomix. Ideally, the moisture in the biobed should be high enough to promote microbial processes and solubilization of pesticides, but it still leaves enough pore space for oxygen to support aerobic processes. Moreover, moisture levels near saturation increase the risk of 
transport of chemicals from the biobed and promote anaerobic processes (Castillo and Torstensson, 2007).

\subsection{Biological activity in the biomix}

\section{Microbial respiration}

Microbial respiration $\left(\mathrm{CO}_{2}\right.$ production $)$ of the biomix pre-incubated at different times ( 0,15 and 30 days) and contaminated with chlorpyrifos (160 mg a.i. $\left.\mathrm{kg}^{-1}\right)$ was evaluated in parallel with the degradation study. The accumulative $\mathrm{CO}_{2}$ production was higher in the biomix pre-incubated for 15 days $\left(433 \mathrm{mg} \mathrm{CO}_{2} 100 \mathrm{~g}^{-1}\right.$ of biomix) compared with the biomix pre-incubated for 30 days (370 mg CO $100 \mathrm{~g}^{-1}$ of biomix) and without pre-incubation (212 $\mathrm{mg} \mathrm{CO}_{2} 100 \mathrm{~g}^{-1}$ of biomix). These results could be attributed to the increment in the proliferation of the microorganisms in the biomix during the pre-incubation principally by the degradation of the components of the biomix, which provide with nutrients and readily available carbon sources, hence, a higher $\mathrm{CO}_{2}$ production. There were no significant differences $(p<0.05)$ in the production of $\mathrm{CO}_{2}$ between contaminated and un-contaminated biomix in the three times of evaluated pre-incubation, probably due to the fact that the added dose of chlorpyrifos did not affect the microorganisms in their respiratory activity.

The microbial respiration (Figure 3) and degradation of chlorpyrifos (Figure 1a) at different pre-incubation times followed a similar behavior, obtaining both the highest values on 15 days of pre-incubation. The respiration rate has been used previously as an indicator of pesticide degradation in biobeds, where the dissipation rates of some pesticides was correlated with basal respiration at 13 different biomix (Castillo and Torstensson, 2007).

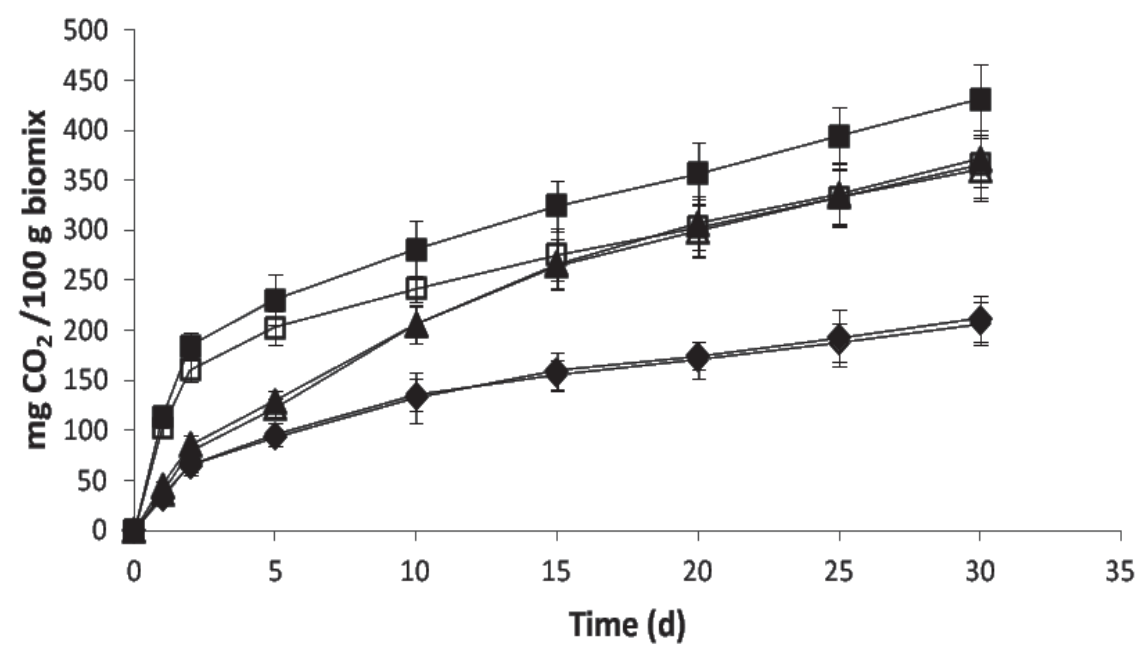

$\neg$ - $\triangleleft$ d Control 0d $\neg-15 \mathrm{~d} \neg$ Control $15 \mathrm{~d} \neg-30 \mathrm{~d} \triangle$ Control $30 \mathrm{~d}$

Figure 3. Microbial respiration in the biomix with different times of pre-incubation (0,15 and 30 days) at initial concentration of $160 \mathrm{mg}$ a.i $\mathrm{kg}^{-1}$ in biomix and $60 \%$ of WHC. 


\subsection{Ligninolytic enzyme activity}

Ligninolytic enzyme activity was higher in biomix contaminated with chlorpyrifos than in un-contaminated biomix in the three evaluated pre-incubation times (Table 4). The enzymatic activity was $2.98 \mathrm{U}$ $\mathrm{kg}^{-1}$ when the biomix was pre-incubated for 15 days, decreasing to $2.37 \mathrm{U} \mathrm{kg}^{-1}$ in the biomix pre-incubated for 30 days. The ligninolytic enzyme activity
(Table 4) and degradation of chlorpyrifos (Figure 1a) at different pre-incubation times followed a similar behavior, obtaining both the highest values at 15 days of pre-incubation. In some works, ligninolytic activity has been correlated to the degradation of several pesticides, such as isoproturon (Castillo and Torstensson, 2007; Von Wirén-Lehr et al., 2001) and chlorpyrifos and TCP (Coppola et al., 2007; Pizzul et al., 2009).

Table 4 Accumulative ligninolytic enzyme activity $\left(\mathrm{U} \mathrm{kg}^{-1}\right)$ after 40 days of incubation at $25^{\circ} \mathrm{C}$ in contaminated and in control biomix at different pre-incubation time ( 0,15 and 30 days) and at different water holding capacity (40, 60 and 80\%). Chlorpyrifos initial concentration of $160 \mathrm{mg} \mathrm{a.i} \mathrm{kg}^{-1}$ of biomix.

\begin{tabular}{ccccccc}
\hline \multicolumn{7}{c}{$\begin{array}{c}\text { Ligninolytic enzyme activity } \\
\left(\mathbf{U ~ k g}^{-1}\right)\end{array}$} \\
\hline \multicolumn{3}{c}{$\begin{array}{c}\text { Pre-incubation } \\
\text { Time (days) }\end{array}$} & & \multicolumn{3}{c}{$\begin{array}{c}\text { Water Holding } \\
\text { Capacity (\%) }\end{array}$} \\
\hline Contaminated & $1.97 \pm 0.1$ & $2.98 \pm 0.3$ & $2.37 \pm 0.1$ & $2.2 \pm 0.2$ & $3.1 \pm 0.2$ & $2.2 \pm 0.1$ \\
Control & $1.68 \pm 0.1$ & $2.28 \pm 0.1$ & $2.07 \pm 0.1$ & $2.4 \pm 0.1$ & $2.2 \pm 0.1$ & $2.1 \pm 0.2$ \\
\hline
\end{tabular}

Considering that the highest chlorpyrifos degradation, the highest microbial respiration and the highest ligninolytic enzyme activity were when biomix was preincubated for 15 days, this pre-incubation time was chosen to evaluate the effect of the moisture content of the biomix in the pesticide degradation. The results showed that enzymatic production was highest in biomix with $60 \%$ WHC $\left(3.1 \mathrm{U} \mathrm{kg}^{-1}\right)$ in contaminated biomix (Table 4). No significant differences were found under the other conditions ( 40 and $80 \%$ of WHC) both in contaminated and un-contaminated biomix with average values of $2.2 \mathrm{U} \mathrm{kg}^{-1}$ of ligninolytic enzyme activity. Similar results were obtained by Castillo and Torstensson (2007). The authors found that moisture levels of $60 \%$ WHC have been shown to be optimum for the dissipation of most pesticides and is suitable for lignin-degrading fungi. Karanasios
(2010) reported that similar levels of activity were observed in most tested biomixtures, where a significant increase in MnP activity was observed on 7 and $14 \mathrm{~d}$ after treatment but its activity returned to levels similar to the other biomix, thereafter.

\section{4 .Conclusions}

Chlorpyrifos is adsorbed efficiently in the biomix prepared with allophanic top soil (Gorbea serie). The isotherms were adequately described by the Freundlich empirical model, where the parameters $K_{f}$ and $l / n$ were higher in the biomix than in the soil, indicating that the contaminant has a greater affinity for the biomix. The pre-incubation period and the WHC of the biomix influenced the degradation of the contaminant, the TCP formation and biological activity, being 15 days of pre- 
incubation and $60 \%$ of WHC, where the highest chlorpyrifos degradation parameters were obtained.

\section{Acknowledgements:}

This study was financed by FONDEF D09R-1006 and by FONDECYT 1090678 projects.

\section{References}

Anwar, S., Liaquat, F., Khan, Q.M., Khalid, Z.M., Iqbal, S. 2009. Biodegradation of chlorpyrifos and its hydrolysis product 3,5,6-trichloro-2-pyridinol by Bacillus pumilus strain C2A1. J. Hazard. Mater. 168, 400-405

Castillo, M.P., Stenström, J., Ander, P. 1994. Determination of manganese peroxidase activity with 3-methyl-2- benzothiazolinone hydrasone and 3-(dimethylamino) benzoic acid. Anal. Biochem. 218, 399-404

Castillo, M.P., Torstensson, L. 2007. Effect of biobed composition moisture, and temperature on the degradation of pesticides. J. Agric. Food. Chem. 55, 5725-5733

Castillo, M.P., Torstensson, L., Stenström, J. 2008. Biobeds for Environmental Protection from Pesticide Use A Review. J. Agric. Food. Chem. 56, 6206-6219

Cea, M., Seaman, J.C., Jara, AA., Fuentes, B., Mora, M.L., Diez, M.C. 2007. Adsorption behavior of 2,4-dichlorophenol and pentachlorophenol in an allophonic soil. Chemosphere. 67, 1354-1360

CIREN. 2003. Descripciones de Suelos y Materiales y Símbolos. Estudio Agrológico de la X Región. Centro de Información de Recursos Naturales (CIREN), Publicación 123. 412 p.

Coppola, L., Castillo, M.P., Monaci, E., Vischetti, C. 2007. Adaptation of the biobed composition for chlorpyrifos degradation to southern Europe conditions. J. Agric. Food Chem. 55, 396-401

Coppola, L., Comitini, F., Casucci, C., Milanovic, V., Monaci, E., Marinozzi, M., Taccari, M., Ciani, M., Vischetti, C. 2011. Fungicides degradation in an organic biomixture: impact on microbial diversity. New Biotechnol. 29, 99-106

Diez, M.C., Mora, M.L, Videla, S. 1999. Adsorption of phenolic compounds and color from bleached Kraft mill effluent using allophanic compounds. Water Res. 33, 125-130

Diez, M.C. 2010. Biological aspects involved in the degradation of organic pollutants. J. Soil Sci. Plant Nutr. 10, 244-267

Fernández, S. 2010. Estudio de un lecho biológico par la degradación del insecticida clorpirifos usado en la producción hortofrutícola. Tesis para optar al grado de Magíster en Ciencias de la Ingeniería mención Biotecnología. Temuco-Chile

Fogg, P., Boxall, A.B.A. 2004. Effect of different soil textures on leaching potential and degradation of pesticides in biobeds. J. Agric. Food Chem. 52, 5643-5652

Fogg, P., Boxall, A.B.A., Walker, A. 2003. Degradation of pesticides in biobeds: The effect of concentration and pesticide mixtures. J. Agric. Food Chem. 51, 5344-5349

Getzin, L.W. 1981. Degradation of chlorpyrifos in soils: influence of autoclaving, soil moisture and temperature. J. Econ. Entomol. 74, 158-162

Gustavson, D.I. 1989. Groundwater ubiquity scores: a simple method for assessing pesticide leachability. Environ. Toxicol. Chemosphere. 8, 339-357

Henriksen, V.V., Helweg, A., Henrik, N., Felding, G., Stenvang, L. 2003. Capacity of model biobeds to retain and degrade mecoprop and isoproturon. Pest. Manag. Sci. 59, 1076-1082 
Iannotti, D.A., Grebus, M.E., Toth, B.L., Madden, L.V., Hoitink, H.A.J. 1994. Oxygen respirometry to assess stability and maturity of composted municipal solid waste. J.Environ. Qual. 23, $1177-1183$

Jaeken, P., Debaer, C. 2005. Risk of water contamination by plant protection products (PPP) during pre-and post treatment operations. Annu. Rev. Agric. Eng. 4, 93-114

Karanasios, E., Tsiropoulos, N.G., Dimitrios, G., Karpouzas, D.G., Menkissoglu-Spiroudi, U. 2010. Novel biomixtures based on local Mediterranean lignocellulosic materials: Evaluation for use in biobed systems. Chemosphere. 80, 914-921

Kotterman, M.J.J., Vis, E.H., Field, J.A. 1998. Successive mineralization and detoxification of benzo[a]pyrene by the white rot fungus Bjerkandera sp. strain BOS55 and indigenous microflora. Appl. Environ. Microbiol. 64, 2853-2858

Maya, K., Singh, R.S., Upadhyay, S.N., Dubey, S.K. 2011. Kinetic analysis reveals bacterial efficacy for biodegradation of chlorpyrifos and its hydrolyzing metabolite TCP. Process Biochem. 46, 2130-2136

Pizzul, L., Castillo, M.P., Stenström, J. 2009. Degradation of glyphosate and other pesticides by ligninolytic enzymes. Biodegradation. 20, 751-759

Racke, K.D., Coats, J.R., Titus, K.R. 1988. Degradation of chlorpyrifos and its hydrolysis products, 3,5,6-trichloro-2-pyridinol, in soil . J. Environ. Sci.Heal. B. 23, 527-539
Racke, K.D., Steele, K.P., Yoder, R.N., Dick, W.A., Avidov, E. 1996. Factors affecting the hydrolytic degradation of chlorpyrifos in soil. J. Agric. Food. Chem. 44, 1582-1592

Romyen, S., Luepromchai, E., Hawker, D., Karnchanasest, B. 2007. Potential of agricultural byproduct in reducing chlorpyrifos leaching through soil. J. Appl. Sci. 7, 2686-2690

Sandar, D., Kole, R. 2005. Metabolism of chlorpyrifos in relation to its effect on the availability of some plant nutrients in soil. Chemosphere. 61, 1273-1280

Spósito, G. 1984. The surface chemistry of soil. Oxford Univ. Press, New York.

Torstensson, L., Castillo, M.P. 1997. Use of biobeds in Sweden to minimize environmental spillages from agricultural spraying equipment. Pestic Outlook. $8,24-27$

Tortella, G.R., Rubilar, O., Cea, M., Wulff, C., Martinez, O., Diez, M.C. 2010. Biostimulation of agricultural biobeds with NPK fertilizer on chlorpyrifos degradation to avoid soil and water contamination. J. Soil Sci. Plant Nutr. 10, 464-475

Vischetti, C., Monaci, E., Cardinali, A., Casucci, C., Perucci, P. 2008. The effect of initial concentration, co-application and repeated applications on pesticide degradation in a biobed mixture. Chemosphere. 72, 1739-1743

Von Wirén-Lehr, S., Castillo, M.P., Torstensson, L., Scheunert, I. 2001. Degradation of isoproturon in biobeds. Biol.Fert. Soils. 33, 535-540 
